Article

\title{
Assessment of Public-Private Partnership in Municipal Solid Waste Management in Phnom Penh, Cambodia
}

\author{
Vin Spoann ${ }^{1, * \mathbb{D}}$, Takeshi Fujiwara ${ }^{2}$, Bandith Seng ${ }^{2}$, Chanthy Lay ${ }^{3}$ and Mongtoeun Yim ${ }^{4}$ \\ 1 Department of Economic Development, Royal University of Phnom Penh, Russian Federation Blvd, \\ Toul Kork, Phnom Penh 855, Cambodia \\ 2 Graduate School of Environmental and Life Science, Okayama University, 3-1-1 Tsushima-Naka, Kita-ku, \\ Okayama 700-8530, Japan; takeshi@cc.okayama-u.ac.jp (T.F.); bandithseng@gmail.com (B.S.) \\ 3 Research Office, Royal University of Phnom Penh, Russian Federation Blvd, Toul Kork, Phnom Penh 12156, \\ Cambodia; laychanthy369@gmail.com \\ 4 Department of Environmental Science, Royal University of Phnom Penh, Russian Federation Blvd, \\ Toul Kork, Phnom Penh 12156, Cambodia; yim.mongtoeun@gmail.com \\ * Correspondence: spoann.vin@gmail.com
}

Received: 6 January 2019; Accepted: 19 February 2019; Published: 26 February 2019

check for updates

\begin{abstract}
The overall responsibility for waste management in Phnom Penh Capital (PPC) has rested with the municipal authorities and contracted waste collection companies. Providing waste collection services is a major challenge for Phnom Penh due to the increasing waste volume and the deficiency of the system under public-private partnership. In response to continuing population growth and urbanization, sustainable management is necessary. This study reviewed the details of the processes and examined the performance of the private sector and local government authorities (LGAs). The study used sustainability assessment, according to a success and efficiency factor method. This assessment method was developed to support solid waste management in developing countries. Multiple sustainability domains were evaluated: institutional, legislative, technical, environmental and health aspects as well as social, economic, financial and critical aspects. The results indicate that the long-term contract design attempts for partnership may actually result in a worsening of the situation by facilitating new ways of concentration, inefficiency and political interest. The limited institutional capacity of the public sectors is a consequence of the inefficient decentralization of municipal solid waste management (MSWM) policies. Public-private partnerships can be neither effective nor sustainable if LGAs and CINTRI co. Ltd. waste collection company do not build proper incentives into their management of the two sectors. Revisiting the legal framework, establishing a facilitating agency that will assist in the design and the nurturing of partnerships, competitive tendering, and transparency and financial accountability are essential elements for PPP on the provision of waste services in PPC.
\end{abstract}

Keywords: public-private partnership; quality assessment; decentralisation; institutional capacity; solid waste collection; Phnom Penh

\section{Introduction}

Recently, there has an increase in interest in addressing the weak performance of the public sector, including reducing costs, improving efficiency and ensuring environmental protection [1]. Public-private partnership (PPP) is a significant approach that can support strong future development of the country's economy and society. Some studies show that the PPP model of waste management in cities such as in Lagos, Nigeria [2] and other developing economies [3,4]. Public-private partnerships 
are often a suggested response to reduce the cost of waste management, improve service quality and make a formal link between public and private sector operations to improve the efficiency of the entire sector. Nevertheless, the process of PPP is often complex and has limitations $[1,5,6]$. Several findings illustrate similar constraints that face the public secto: financial challenges, low quality personnel, outdated equipment, laborious procurement procedures, rigid working schedules, constraints on management changes, poor supervision and corruption $[1,6,7]$. Post [8] found that the determining factors for cost-effectiveness in privatized solid waste collection are quality of service operation, income level in the service area, technology used and success of fee collection. Since waste collection services in Phnom Penh have been awarded to a single company via a long-term, confidential contract as part of PPP, collection service provision has been difficult to monitor; the fee structure has not improved household waste collection systems; collector employment conditions do not incentivize performance [9]; and citizens living in peri-urban communities often throw out waste in open spaces or illegal dumpsites due to the lack of the access to collection services. Similar to other fast-growing cities in the region, Phnom Penh has struggled for years with inefficient household waste collection. The waste management in this city is labor-intensive. It is a low-margin business and the collection service provision has been delivered by six different organizations since 1994 (see Figure 1).

This study assessed the performance of public and private institutional arrangement in municipal waste collection in Phnom Penh. Consideration was given to both regulating agencies and service providers. The analysis paid attention to decentralization and privatization policies that have been implemented in Cambodia since 2009. These have changed institutional arrangement and administrative functions. The operational performance of contracted waste collection services was assessed using an amended version of the multiple sustainability assessment developed by Zurbrügg et al. [10].

\section{Public and Private Sector Actors in Municipal Solid Waste Management (MSWM)}

Both public and private sectors are active in addressing MSWM in developing countries [7]. Actors involved in solid waste management are introduced below, noting their particular role, responsibilities, benefits and constraints. Public sector agencies have an overall responsibility for urban waste management. Leitmann [11] noted in most Asian cities there is no single institution responsible for urban environmental management issues. The prioritized sectors in urban environmental management issues are solid waste, water supply and sanitation and air quality [12]. Hence, the criteria for choice of the public or private service delivery are to be deeply considered. Questions are often asked: "could an assigned role to local governments and expanded role of private sector help to alleviate the solid waste problem by improving the efficiency and coverage of waste services?" (Bartone et al. [13] and Memon [12]).

The Government of Cambodia has clearly identified the need for the improvement of public sector services and suggested a reform of civil services and public enterprises. With this view, the plan for the development of SWM service considered three principles: (a) government endorsed services; (b) informal sector service provision; and (c) partnerships established with the public-private sector $[14,15]$. In light of these principles, the reforms to improve the solid waste management were introduced and role, right, and legislative obligations were clearly defined in sub-decree 113, inter-ministerial declaration and Phnom Penh' directive on urban solid waste management. The decentralization of institutional function and responsibility is specifically targeted the quality and the coverage of service and level of environmental protection [16]. However, the question that needs to be answered after reforming policy is: "what challenges and constraints have public sector bodies faced in exercising those right and responsibility?". Evidently, the report from the National League of Local Councils reported that only $17 \%$ of municipal authorities have integrated solid waste management issues into their five-year development plans, even though the reform policy has been introduced. NLLC [17] and Vong [18] studied the challenges of decentralization on urban waste management in Cambodia; however, the few studies provide little insight into the assessment of rights and responsibilities of public-private partnership for solid waste management. 


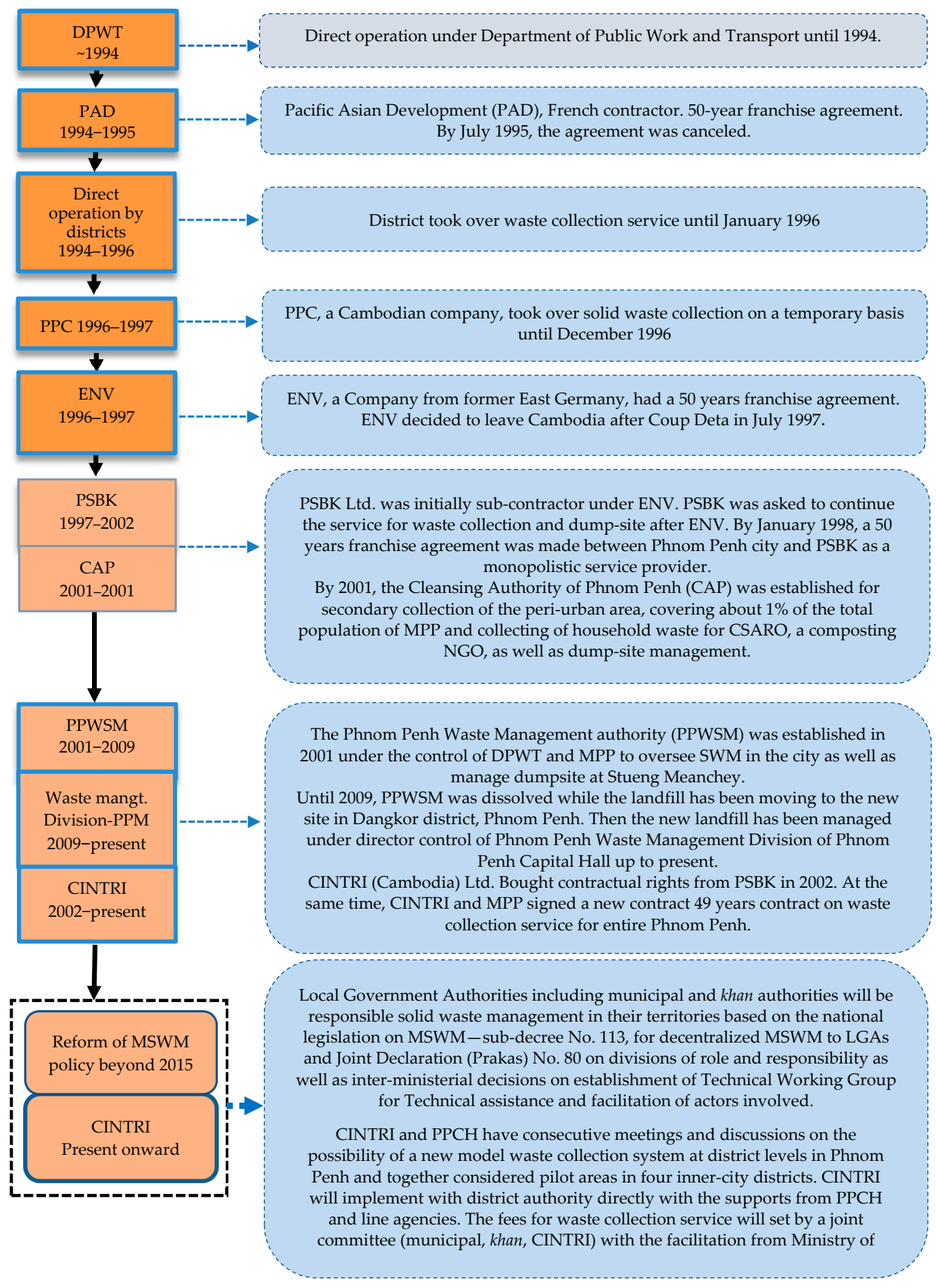

Figure 1. The flow of MSWM service providers in PPCH (author modified after $[15,19])$.

\section{Solid Waste Management and the Public Sector}

\subsection{National Level}

In a recent sub-decree, No. 113 enacted on 27 August 2015, urban solid waste management was decentralized and responsibility was given to provincial, municipal and district levels [16]. This transformation allowed district/municipal administrations to deliver local services to the private sector. The Ministry of Environment still maintains responsibility for setting regulations, monitoring and evaluation, and levying penalties for waste management non-compliance. The Ministry of 
Interior has the mandate to support the Ministry of Environment through coordination with other relevant agencies in capacity-building and experience sharing. The Ministry of Economics and Finance coordinates with the Ministry of Environment and the Ministry of Interior in establishing tariff rates for urban solid waste management services (see Figure 2). Figure 1 shows the basic components of the MSWM system in Phnom Penh, with CINTRI bearing responsibility for waste collection services. Evidently, these components are the basic requirements for Phnom Penh City Hall ( $\mathrm{PPCH})$ in private sector waste services [19].

National Level:

1. Ministry of Interior (MoI): Supporting in law and regulation enforcement; and permission for the location of dumpsites

2. Ministry of Environment (MoE): Legislative body and introducing policies and guidelines on SWM. Providing monitoring works and indirect supervision on SWM to local government agencies.

3. Ministry of Public Works and Transport: Manage and control all kinds of transportation facilities, sewage network, wastewater treatment plans; and manage and maintain all public sanitation services in the country

4. Ministry of Tourism: Promoting city cleaning in the tourism industry in Cambodia

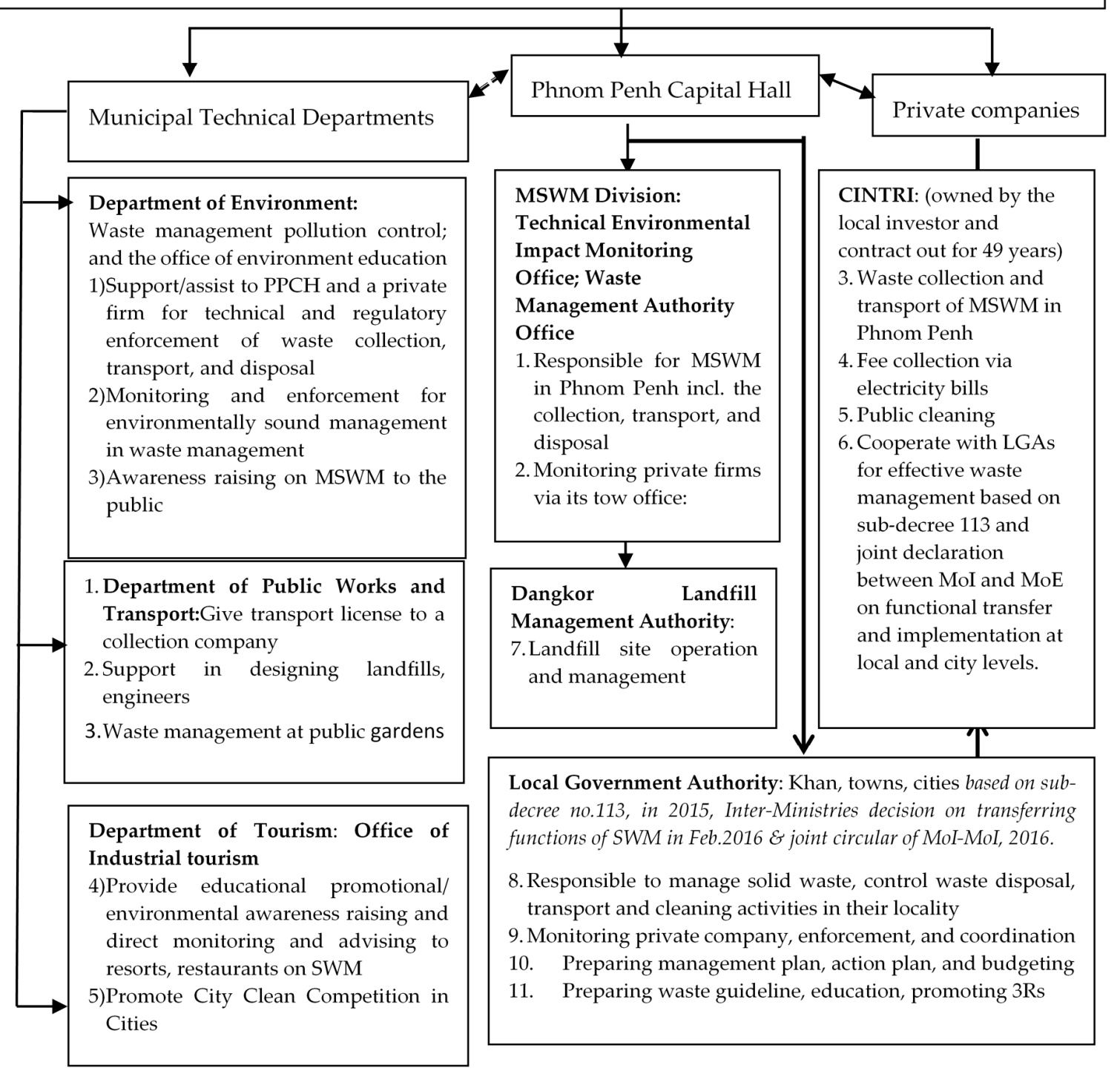

Figure 2. Current Institutional Arrangement of MSWM in Phnom Penh Capital (author modified after [19]). Note: NB: Direct governing; ministerial/horizontal governing. 


\subsection{Local Government Units}

Figure 1 represents the municipal solid waste situation over the last 30 years in Phnom Penh. The evolution of MSWM in Phnom Penh has seen responsibility shift several times to different parties from a public waste management to a public-private partnership model. After the civil war ended in 1993, MSWM functioned under the responsibility for municipal cleaning of Department of Public Work and Transport (DPWT) of PPCH, providing MSWM services until 1994. Due to rapid growth and limited capacity $[19,20]$, PPCH entrusted its MSWM services to private contractors with franchise agreements to collect, transport and dispose of municipal waste. Nevertheless, services were not efficiently provided, according to the terms of specifications in the contractual agreement [6]. This was because service providers often faced financial difficulties, such as unclear tipping fee criteria, and service quality on waste collection, fee collection efficiency, and unwillingness to pay for services [19].

\subsection{Private Operator on Solid Waste Service}

In Cambodia, after nearly three decades of unrest in civil society, the public sector's performance deteriorated, due to a lack of an organizational framework, physical losses, spiritual suffering, inadequate government services and lack of resources. After the re-establishing of Kingdom of Cambodia in 1993, the new coalition government attempted to introduce a private sector participation policy under the Rectangle Government strategy II [20]. The strategy aimed at promoting private sector involvement in infrastructure and service management to reduce poverty in the country.

There was an exclusive agreement between PPCH and CINTRI for 49 years to deliver the major responsibilities of MSWM to CINTRI on the provisions of garbage collection services from 2002 until the present. Additionally, there also was also an agreement between CINTRI and Electricity of Cambodia Authority (EDC) on waste fee collection. The fee collection was included in the electricity bill to ensure the effectiveness of cost-recovery. However, the long-term single-service provider contract between CINTRI and the government was confidential, and even PPCH rarely received annual reports from CINTRI from the time when the contract began in 2002. It was observed that PPCH had limited ability to monitor CINTRI and lacked legal avenues to incentivize improvements to its performance [9]. Responding to the above-mentioned problems, PPCH adopted a local regulation, No. 593, to enforce punishment and allocation of fines to local authority funds of up to $60 \%$ of the total fines [19].

\section{The Study Area: Phnom Penh Capital}

Phnom Penh Capital was selected as a study area where the MSWM public-private partnership was implemented within considerable contextual complexity. In 2015, the total population of the city was 2.06 million [21]. In the last 10 years, the city has expanded the boundaries of its administration in association with economic growth and structural changes. These cover $678 \mathrm{~km}^{2}$, and include 12 districts and 96 communes (Figure 3). The population density averages about 2213 people $\mathrm{km}^{-1}$ [22] and the area of the city has expanded up to a $100 \mathrm{~km}$ radius around the city center [23]. PPC is the center of the business and commercial hub, government administration and agglomeration of the economy; the urban sector share accounts for $50 \%$ of the country's GDP [24]. 


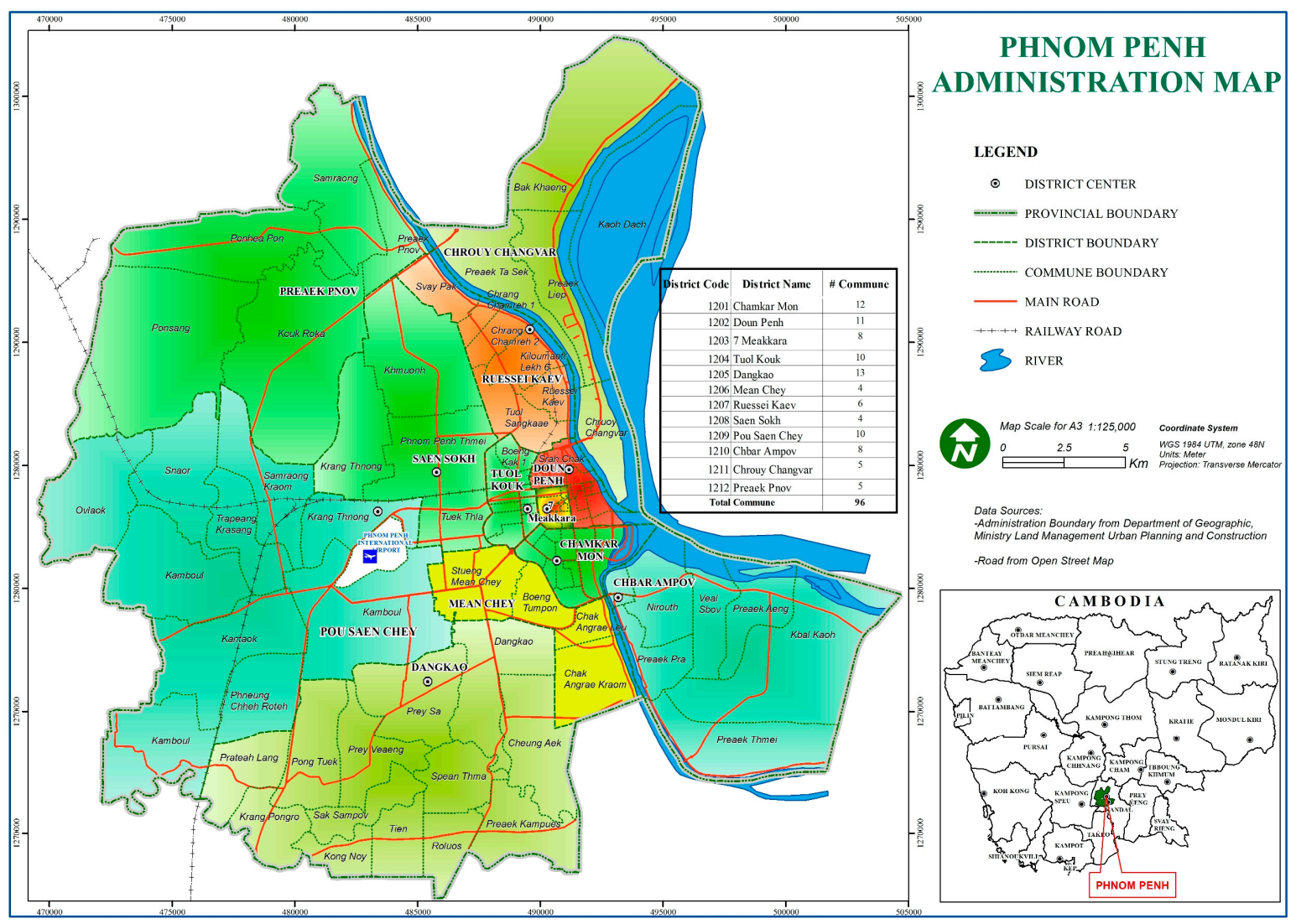

Figure 3. Map of Phnom Penh Capital, Cambodia [24].

\section{Methods and Materials}

The data collection was derived from the goal of the study; an evaluative assessment of the public and private sectors' performance was conducted. Joseph [25] and Visvanathan et al. [26] indicated that that achievement of a sustainable model of waste management requires an integrated approach, including combined solid waste management elements (e.g., waste generation, collection, treatment, final disposal, etc.), stakeholder involvement (waste processors) and cooperation between waste management and other related urban systems. For this study, the current context of SWM in Phnom Penh capital was established and the private operator, namely CINTRI, as well as government actors, was addressed. Key issues related to quality of service, operational quality, legal and institutional landscape between the municipality and a private contractor were examined. The case study approach allowed for both quantitative and qualitative evaluation variables to be considered. Further, it offered the opportunity to assess the causal link between actions and outcomes in a real-life situation. An approach used by Massoud et al. [1] in his study was applied in assessing public vs. private SWM management. Published documents from government offices, project reports, scientific papers and academic literature were also reviewed; moreover, the data in this study were drawn from a combination of primary sources via focus group discussion (FGDs) during an eight-month project from November 2016 to June 2017 in Phnom Penh. Sixty key informants, including representatives from PPCH, Ministry of Environment, Department of Environment in Phnom Penh (PPDOE), CINTRI waste collection Company and LGA officers of the twelve districts participated in the FGD's sessions. The FGDs focused on waste collection service performance, quality of services, system improvement, legal enforcement, stakeholder involvement, and challenges and limitations to PPPs for SWM. 


\section{Performance Indicators for Assessing Sustainable Waste Management}

In Phnom Penh, the method of evaluating operational components has repeatedly been a source of imprecision. The study did not estimate costs of private waste operators and public sector agency due to limited information on costs. The study used sustainability assessment by a success and efficiency factor method. This was developed by Zurbrügg et al. [10] to support solid waste management in developing countries. To assess "critical aspects" that influence success or failure, a set of guiding questions was developed. The guiding questions are listed in Table 1.

Table 1. Key questions to be considered for assessment domains.

\begin{tabular}{|c|c|}
\hline Sustainability Domain and Indicator & Questions to be Covered \\
\hline \multicolumn{2}{|l|}{ 1. Technical Aspects } \\
\hline $\begin{array}{ll}- & \text { Collection rate } \\
- & \text { Collection coverage } \\
- & \text { Collection efficiency }\end{array}$ & $\begin{array}{l}\text { - Is the technology appropriate to existing local } \\
\text { infrastructure conditions? } \\
\text { - Can the collection facilities cope with and adapt to possible } \\
\text { changing conditions (e.g., quantity or nature of waste)? } \\
\text { - Has the most cost-effective technology been selected for } \\
\text { CINTRI services? } \\
\text { - In relation to the total amount of waste generated, what \% of } \\
\text { waste is collected? } \\
\text { - Relative to the total population, what \% of people are served? } \\
\text { Quantity and physical property of waste bins in } \\
\text { commercial areas }\end{array}$ \\
\hline \multicolumn{2}{|l|}{ 2. Health and Environmental Aspects } \\
\hline $\begin{array}{ll}- & \text { Collection efficiency } \\
- & \text { Cleanliness } \\
- & \text { Illegal dumping }\end{array}$ & $\begin{array}{l}\text { - } \quad \text { Illegal disposal practices and areas as percent of } \\
\text { waste generated } \\
\text { - } \quad \text { Is collection performance adequate and sufficiently clean? } \\
\text { - } \quad \text { Do the crew and cleaning workers' well-being and health? } \\
\text { - Is community wellbeing and health safeguarded? } \\
\text { - } \quad \text { Does the study support a modernized and sustainable system? }\end{array}$ \\
\hline & \\
\hline
\end{tabular}

How are tasks performed?

Are MSW systems were being delegated effectively?

- $\quad$ Personnel capacity and employment

- $\quad$ Role and Responsibility of stakeholders

How do LGAs monitor and control waste collection service?

- Institutional framework Are there sufficiently skilled staffs; is there a legitimate workforce for MSWM?

- Labor tenure

- Coordination and Cooperation What are the management gaps for LGAs and CINTRI? Is the management framework workable and feasible? How well is MSWM functioning? Is there effective cooperation with other stakeholders in the system that will allow for the structuring and maintenance of successful interaction?

\section{Financial Viability and Economic Aspects}

- financial and fiscal viability

- Willingness to cooperate

- Accountability

\section{Social Aspects}

Level of fee collection efficiency and payment vehicles Budget allocation for waste management as $\%$ of the total budget Operation and maintenance cost under LGAs' responsibility Level of cost-sharing amount shared holders
- $\quad$ MSWM activities/Campaign

- Stakeholders' participation

- Communication mechanisms
Do residents and local authorities believe that waste services are socially beneficial; are they supportive of the services? Has consideration been given to community participation/ involvement in the waste services providing by CNTRI? How do they communicate (public-private and community) with each other? 
Table 1. Cont.

6. Policy and Legislative Aspects

$\begin{array}{ll} & \begin{array}{l}\text { Are the policies and legalization sufficient; are they implemented in } \\ \text { such a manner as to facilitate the work of current SWM? }\end{array} \\ \text { - } \quad \text { Relevant legislation, strategies } & \begin{array}{l}\text { Do the decentralized SWM receive support from the private } \\ \text { operator and local government authorities? If not, what are the }\end{array} \\ \text { - } \quad \text { Legal frameworks for LGAs } & \begin{array}{l}\text { limitations or gaps? } \\ \text { Do the waste services comply with quality standards of service as } \\ \text { define in the contractual agreement? } \\ \text { How does the public sector enforce the policy and legal frameworks? }\end{array}\end{array}$

Sources: Author adopted from $[1,10,15,19,27,28]$.

\section{Results and Discussion Waste Generation and Composition}

From 1995 to 2010 and then to 2015, MSW generation in Phnom Penh increased rapidly from 0.136 million tons in 1995 to 0.409 million tons in 2010 [28] and then to 0.681 million tons in 2015 [15,29]. Waste generation rates are affected by socio-economic development, level of industrialization, urbanization, excessive consumption of modern life and climate. In brief, the conjunction of economic prosperity and rate of urbanization greatly increased solid waste volume. Table 2 shows the quantity of municipal solid waste disposed at the landfill during 2004-2015. In relation to the total waste generated in the city, about $20 \%$ was not collected. In 2003, gross generation rate per capita was about $0.74 \mathrm{~kg} \cdot$ day $^{-1}$ [30] and $0.762 \mathrm{~kg} \cdot$ day $^{-1}$ in 2013. It is projected that it will be $1.24 \mathrm{~kg} \cdot$ day $^{-1}$ by 2030 [18]. The major components of the refuse are kitchen waste (63.3\%), plastic (15.5\%), grass/wood (6.8\%) and paper/cardboard (6.4\%). Beyond this, the other waste collected includes metal, glass, rubber/leather, textiles and ceramic/stone. These classes account for less than 3\% of the total. All waste sources contain high moisture content, ranging from $45 \%$ to $69 \%$ [28].

Table 2. Population, GDP and amount of waste generated from 1994-2015 [15].

\begin{tabular}{|c|c|c|c|c|}
\hline \multirow{2}{*}{ Year } & \multicolumn{2}{|c|}{ Population in Million } & \multirow{2}{*}{$\begin{array}{c}\text { GDP } \\
\left(\text { USD.Capita }^{-1}\right)\end{array}$} & \multirow{2}{*}{$\begin{array}{l}\text { Waste Amount in Phnom Penh } \\
\text { (tons. year } \\
\text { (1) }\end{array}$} \\
\hline & Cambodia & Phnom Penh & & \\
\hline 2004 & 12.824 & 1.044 & 389 & 227,910 \\
\hline 2005 & 12.963 & 1.108 & 454 & 266,781 \\
\hline 2006 & 13.103 & 1.177 & 513 & 324,159 \\
\hline 2007 & 13.245 & 1.249 & 575 & 343,657 \\
\hline 2008 & 13.868 & 1.326 & 739 & 361,344 \\
\hline 2009 & 14.085 & 1.438 & 765 & 393,141 \\
\hline 2010 & 14.302 & 1.504 & 830 & 409,335 \\
\hline 2011 & 14.521 & 1.570 & 853 & 442,469 \\
\hline 2012 & 14.741 & 1.637 & 915 & 492,380 \\
\hline 2013 & 14.962 & 1.704 & 1036 & 531,340 \\
\hline 2014 & 15.184 & 1.770 & 1137 & 617,489 \\
\hline 2015 & 15.405 & 1.835 & 1237 & 617,905 \\
\hline
\end{tabular}

\subsection{Waste Collection, Transportation and Disposal}

Waste collection and transportation in Phnom Penh city has improved significantly. The collection rate was $80 \%$ in 2010 [31] and increased to $82.1 \%$ in 2015. Figure 4 presents the amount of collected and uncollected solid waste in Phnom Penh. The total amount of uncollected waste calculated was about $7943 \mathrm{Mg}$ per month on average or $264 \mathrm{Mg}$ daily. The private operator has put more efforts into collecting waste from some suburb communities, over others. In fact, service is often provided to the beneficiary's locations rather than low income communities. The recent study noted that of 41 Sangkats in the outskirts, 20 had no households that registered as receiving collection services [32]. According to the results from consultation meeting with LGAs, the waste collection frequency is relatively low in 
peri-urban communities and amounted to once or twice per week, even though CINTRI has claimed high service coverage rate. Based on CINTRI data, six districts have received the collection services at rates ranging 20-60\% (Khan Po Sen Chey, Khan Chroy Changva, Khan Prek Phnov, Khan Sen Sok, Khan Chbar Ampov and Khan Mean Chey).

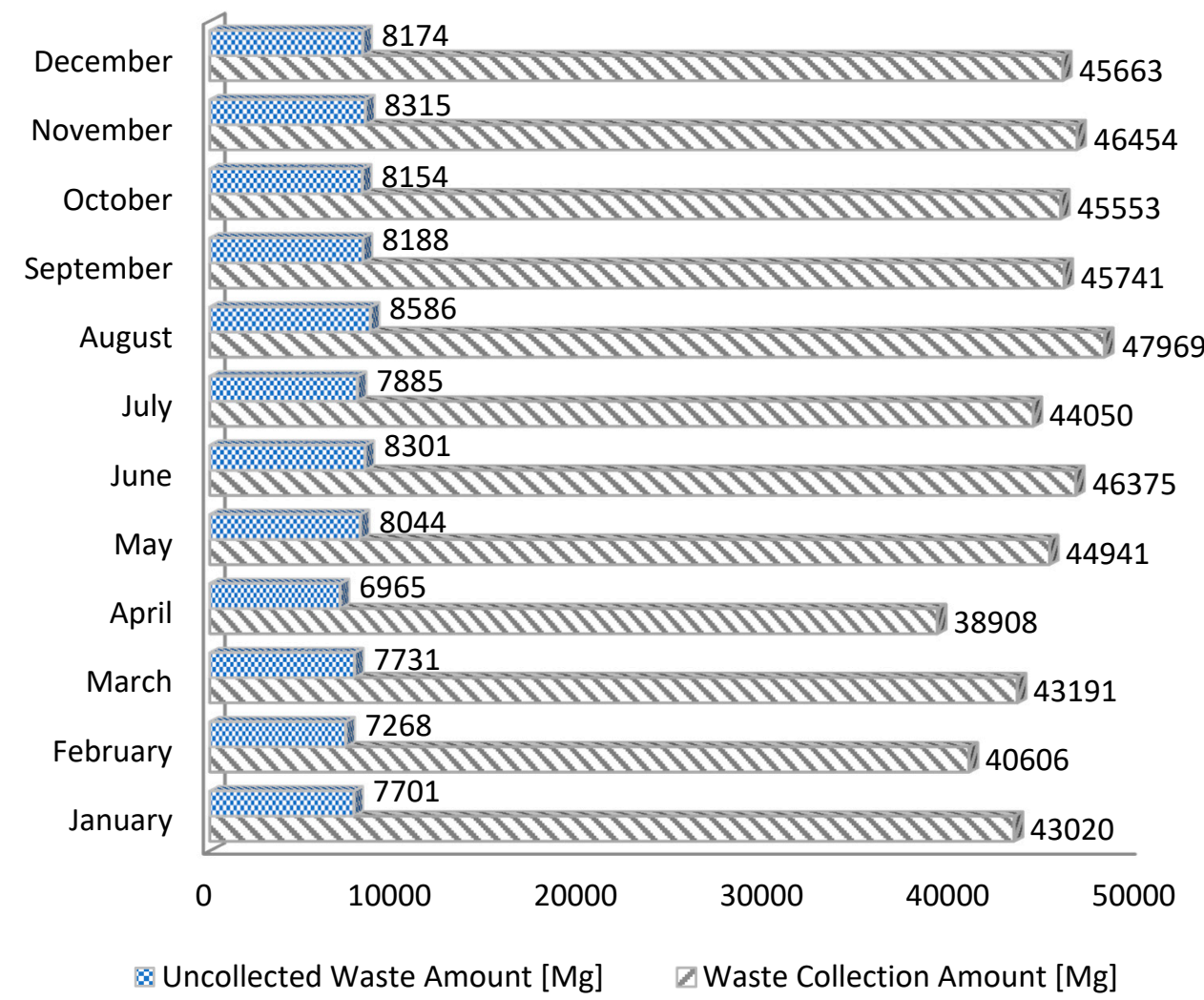

Figure 4. Amounts of collected and uncollected MSWM in Phnom Penh, 2015 (author calculated after [19]).

The transportation efficiency of municipal waste collection service depends on technical input and crew personnel. The inadequate transportation facilities of CINTRI have necessitated a shift in the collection time and transportation routine from day to night time for some inner city districts and commercial areas. Spoann et al. [15] indicated that the collection capacity of CINRTI is limited not only in terms of facilities but also lacks personnel resources. In other words, the main constraint on waste collection is the lack of personnel due to low compensation rates.

MSW is transported to Dangkor District landfill site, $16 \mathrm{~km}$ from the city center. The site has been under operation since 2009. Initially, the 26-ha landfill was designed to serve as a sanitary landfill. CINTRI is obligated to operate daily cleaning, collection and transportation to the landfill (Figure 5). The city does not have a pre-treatment facility and does not treat waste before transferring it to the landfill site, thus the site's lifespan is shortened. The amount of waste generated daily is anticipated to exceed 2200 tons by 2020. This will significantly increase burden on MSWM [19]. The uncollected waste is an additional problem-about 100-200 tons of waste is not being collected and is instead self-treated [9]. Most households burn, bury or dump their waste in their land pots and open spaces in the community $[9,19,30]$. This is illegal dumping, which has been prohibited by regulations and city orders. However, waste disposal practices became a topic of critical discussion among stakeholders. Evidently, many complaints against CINTRI's performance from residents have reached the local authorities. The results of FGD indicate that the complaints have reduced noticeably, and some heaps of uncollected waste have been replaced by large containers. This essentially resulted from the 
responsibilities of SWM being delegated to LGA units and the adoption of sub-decree 113 on urban waste management to local government levels.

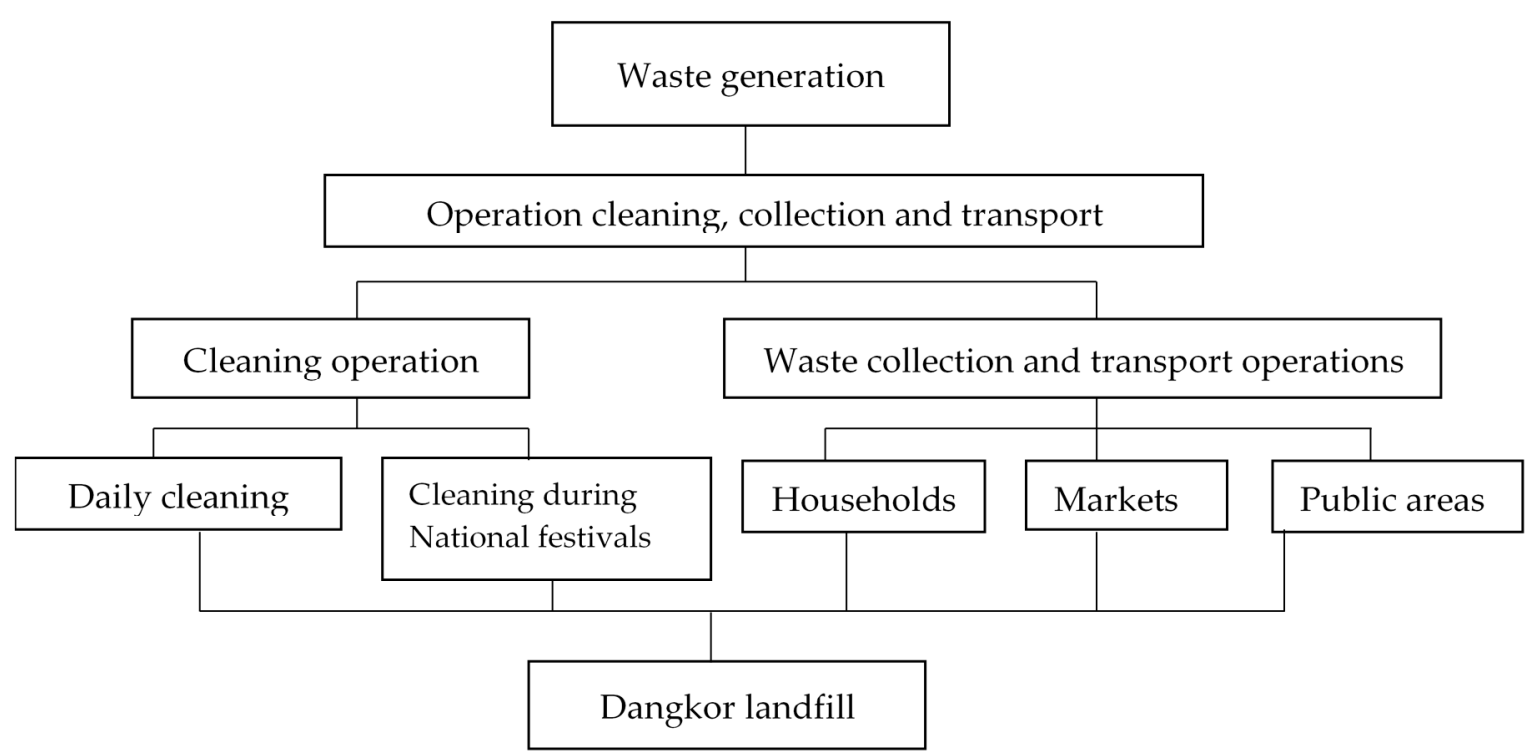

Figure 5. Basic components of solid waste management SWM illustrated by CINTRI Waste Collection Company, Phnom Penh.

\subsection{Public and Private Sector Role}

In many cities of developing countries, including Phnom Penh in Cambodia, the private sector is regarded to be strong at design and operation and the government is deemed to be weak in regards to management and operation. Massoud et al. [1] also noted this flaw is known when there are changes to the politicians in power. Accordingly, government bodies should be involved in policy-making, introducing the local ordinance and carrying out legislative obligations, supporting and protecting the public interest and allocating funds for LGAs as public partners. The private sector, CINTRI waste collection company, has significant strengths in management and control of cost recovery, the extension of services in new urban development areas, design and use of technology (Figure 4). More importantly, CINTRI is the sole service provider partnering with LGAs, which has a high profile and resources to meet specific performance criteria in the future. However, the gap between demand and supply side of infrastructure and service still exists as their focus is varied. In this case study of Phnom Penh waste management, since the reform is new and a contract agreement is a long-term business, one of the practical options is to strengthen the role of the public with respect to decentralization and private sector with respect to private sector participation. The delegation of functions to local government units is more useful because it may help to improve the level of service, and is targeted to improve accountability and effectiveness of LGAs.

\subsection{Monitoring and Regulations}

Policy and regulation concerning solid waste management at the national and Phnom Penh Capital levels are shown in Figure 6. Several regulations have been ratified since establishing the Ministry of Environment (MOE). The previous failure in providing collection services promoted the recent decentralization of MSWM. This was enforced by RGC sub-decree No. 113 [16] and the joint-declaration between MOI and MOE on establishing the implementation of urban waste management at local government levels. This regulation aims to improve the sustainability of MSWM, in a manner that is both transparent and accountable, to preserve environmental safeguards and stability. The new regulations have shifted the responsibility to sub-national government including provincial, municipal and district authorities, to control and monitor the performance of private 
operators. Massoud et al., [1] argued that the success of PPP depends on the competence of the government in developing good monitoring practices and regulations. In contrast, the capacity and competence of regulatory agencies seems to be limited to the achievement of fruitful enforcement for several reasons (e.g., political manipulation and politician interest). Denney [9] noted cases in which the reforming solid waste management in Phnom Penh led to problems of waste collection, especially for the existing waste collection system within a difficult wider political context, the reform of the SWM system in a limited space, and the lack of a political will to deal with the problem of solid waste. Similarly, the focus group discussion reported that LGAs are encouraged to try to continuously work with CINTRI, rather than to work against them in an effort to revise the term of the contract. Asian Foundation's report cited by Denny [9] described:

CINTRI's political protected ... control of guarantee revenues irrespective of performance is the root cause of the poor performance of solid waste collection in Phnom Penh.

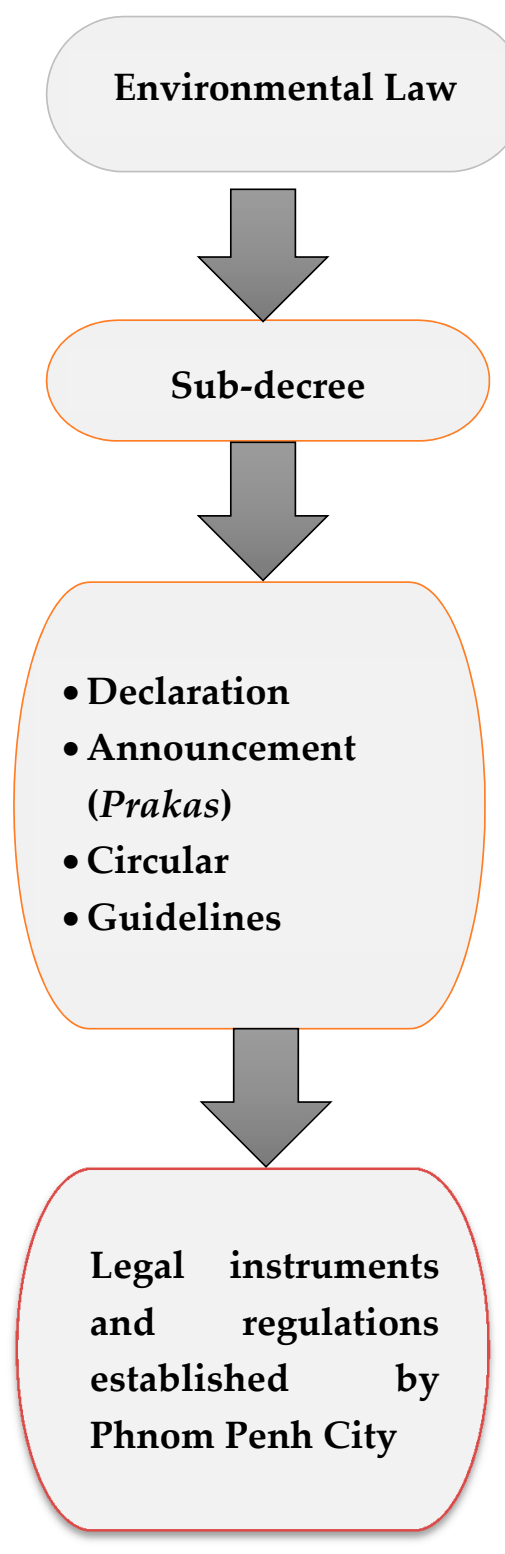

Law on Environmental Protection and Natural Resource Management, 1996

> Sub-decree\#113 on urban solid waste management, 2015

$>$ Sub-decree \#36 on solid waste management, 1999

$>$ Sub-decree\#16 on e-waste management, 2016

$>$ Sub-decree\#168 on plastic bags management, 2017

$>$ Sub-decree $\# 42$ on the control of air pollution and noise disturbances, 2000

$>$ Sub-decree\#27 on water pollution control, 1999

$>$ Sub-decree\#72 on environmental impact assessment

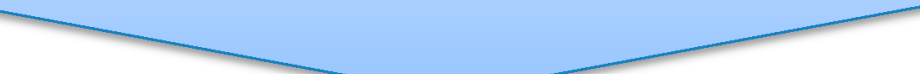

> Joint Ministerial Prakas on the usage of sanitation service fund for the implementation of urban solid and liquid waste management of subnational administration, 2015

$>$ Joint declaration $\# 80 \mathrm{MOE}, \mathrm{MOI}$ on the implementation of solid waste management in province/municipality, 2003

$>$ Prakas on industrial hazardous waste management

> Technical Guideline on MSWM in Cambodia, MOE, 2016

> Notification\#13 on waste storage, cleaning, discharge and penalty of improper waste disposal in Phnom Penh capital, 2013

$>$ Instruction plan \#08 on waste separation promotion in Phnom Penh Municipality, 2010

$>$ City Instruction\#16 on penalties on waste disposal in public areas, 2010

$>$ Draft strategy and methodology for improving waste management and cleaning, collection and transport of solid waste in Phnom Penh Capital, 2013

$>$ Notification \#12 on garbage and solid waste management in Phnom Penh Capital, 2019

Figure 6. Legislation and local regulations related to solid waste management. 
The finding on the challenges of LGAs in waste management is a critical movement. Spoann et al. [15] argued that proper management needs only a solid legal foundation. They deemed law enforcement to be one of the most important duties of the public authorities. In addition, limits in relation to incentives results in irregular monitoring and evaluation [15]. The focus group discussion (FGD) indicated that regulatory agencies, such as Department of Environment and LGAs, are affected by inadequate financial resources and facilities, resulting in weak enforcement and less attention to assigned tasks. However, Kum et al. [20] showed that it is politically and practically challenging for government regulatory units to enforce compliance with regulations where regulatory agencies are ignored and work with less commitment. Therefore, policy support and a localized legal framework need to be developed to ensure the effectiveness of law enforcement, monitoring of the private operator and controlling illegal dumping.

\subsection{Institutional Management and Operational Framework}

Multi-national government agencies and transnational corporations play a vital role in the long-term development program [33]. RGC highlighted the need to develop public services and suggested alternative service provision through public-private sector partnership [14,15]. COMPED [19], JICA [34] and Spoann et al. [15] concluded that weaknesses in institutional organization are cause by four problems: lack of accountability and transparency, unclear delineation of roles, political manipulation and limited commitment in relation to regulatory measures enforcement.

It has been generally proven that developmental strategies must go beyond mere technical considerations and address the aforementioned set of the issues to achieve sustainable and effective waste management [1]. As such, a national waste management strategy and action plan for Cambodia [35] should reflect the local context and institutional arrangement landscape. The responsibilities of LGAs have come with the resources and obligated duties. There are at least seven responsibilities supporting the functions executed by local government units addressed in Sub-decree 113. In light of new reform of solid waste management regulations, LGAs are seemingly realized to improve the operational performance as the exclusive agreement with CINTRI is made directly with individual Khan. However, the municipality and Khan also have understood that private operator alone cannot fulfill its tasks without support and interventions from LGAs and stakeholder involvement (Figure 7). The focus group discussions suggest that CINTRI has to prepare a proper waste collection schedule; the proposed schedule needs to be reviewed by LGAs; and then it must inform the citizens in Khan and Sangkat before implementation. The reforms of a solid waste management system in Phnom Penh are meant to lead to institutional and organization change and fund reallocation from the national government to local government units. In addition, Phnom Penh Capital administration is currently establishing the local legal instrument (e.g., local ordinance on solid waste management in Phnom Penh) for enhancing instructional capacity, responsibility, right and resources on the implementation of urban waste management at LGAs context. In some places, decentralization improves the level of environmental cleanliness and is also possible for promoting clean municipal or Khan through Clean City Competition. 


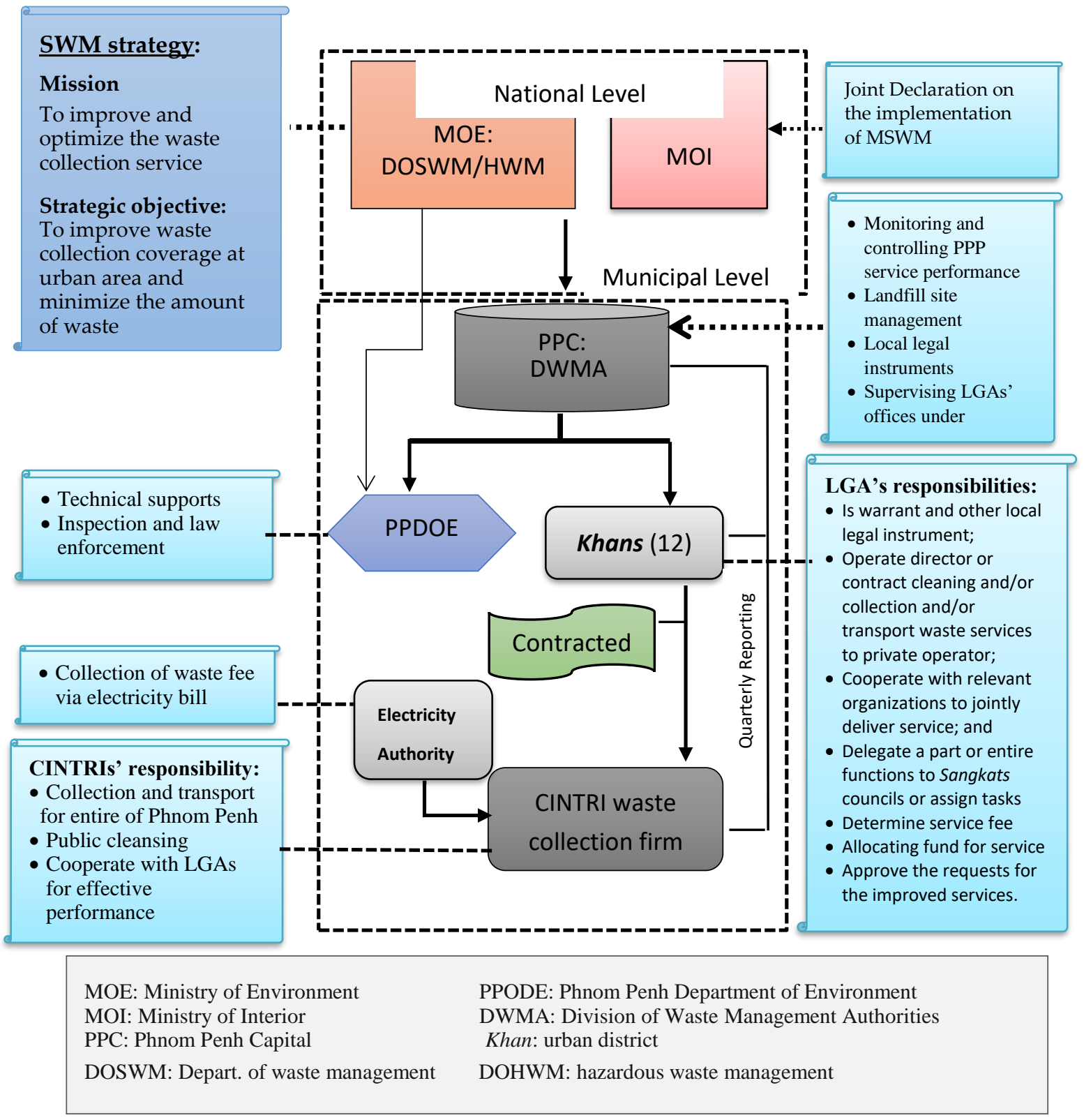

Figure 7. Overview of decentralized municipal solid waste management in Phnom Penh.

\subsection{Stakeholder Involvement}

Identification of the stakeholders and their interests is important to gain their participation and involvement in various waste management activities [25]. In Cambodia, cooperation with private service providers has reportedly been problematic: less than one-third of the service providers in Cambodia report to government units regularly [17]. The municipal and district administrations have faced constraints and limitations in involving private operators in the expanding of the service areas to suburban communities where there are fewer beneficiaries and they are underserved by the road infrastructure. Joseph [25] noted that it is not an easy task to plan and implement an action plan to achieve efficient waste management without the active involvement of relevant stakeholders. Joseph [25] and Wilson and Tormin [29] suggested that efforts should be made at all levels to minimize the volume of generated waste and manage municipal solid waste in a safe manner. Hence, reforming waste management in Phnom Penh will help to promote participation and provide a platform for a sound working environment. Despite years of promoting decentralization reforms, the level of 
participation is still limited. This is because solid waste has fewer entrenched political interests than some other sectors [9]. According to the focus group discussions, the issues of lacking accountability and transparency in competition have likely rendered less involvement from other private operators. This has led to unreliable and ineffective performance during the period of CINTRI carrying out its 49-year-long contract for waste collection services in Phnom Penh.

\subsection{Quality of Services}

Quality testing considers the actual frequency of collection and the cleanliness of the service [36]. According to Spoann et al. [15], service quality is still low and lacks sufficient hygiene. The collection frequency and schedule are also inadequate and affect collection time. Collection frequency was the most important factor affecting user satisfaction, especially in peri-urban areas. The recent study on knowledge, attitude, and practices of household waste management in suburbs of Phnom Penh indicated the situation of SWM is not satisfactory owing to the responses of $78.68 \%$ from within service using households and the collection frequency is $46.19 \%$ for twice a week and $22.34 \%$ for once a week [37]. Likewise, the study also indicated that the technical capacity and skills of LGAs is limited-they are not actually accepting their duty for management services in their respective areas. Inadequate service provision causes waste to accumulate in bins and community temporary storage points or become littered on vacant land. There are other significant issues. It is understood that operational performance depends on the quality of services provided and reliability technically based on technical input. It is identified that the problem of waste management in Phnom Penh can be split into three areas: (i) the volume and composition of waste and the capacity of the landfill site; (ii) the nature of collection provision by CINTRI [9]; and (iii) institutional and LGA capacity in coping with waste management at their respective territories. Evidently, the main reasons service provision is inadequate are because of lacking collection facilities and limited numbers of personnel. This is evident from the pilot implementation in Khan Daun Phenh of Phnom Penh [23]. In addition, the statements from the LGAs during the group discussion can be summarized as follows: lack of waste collection crew and compact trucks are the main issues for CINTRI. It is reported that low salaries for collection crews is considered as a constraint on improvement of regular waste collection, even though CINTRI strives to collect household waste 3-4 times daily. In addition, CINTRI is also responsible for public areas, street cleaning and waste clean-up actions during festivals. These tasks place an additional burden upon the collection company. Another shortfall of service quality is the cleaning of anomalous illegal dumping sites; LGAs request that CINTRI collect from the communities. According to Denney [9], there are about 100 to 200 tons of uncollected waste that remain self-treated-i.e., households dump, burn, and discard their waste in empty land and illegal dumping plots. Thus, the new reform policy to transfer duties and responsibilities to LGA (e.g., Khan/municipal authorities) are likely to face delays in reinforcement and will require revisions to separate the contract between LGA and CINTRI. The limited resources and capacity of the public-sector to cope with uncontrollable dumping sites leads the decision-makers to choose this existing waste operator as the long-term running business firm in waste service. However, Phnom Penh City Hall remains reluctant to pass over this task to CINTRI for all Khans, unless the terms of the contractual agreement are responsibly rendered to reflect the public interest and unless there is efficient performance.

\subsection{Personnel Resources and Labor Conditions}

The retrenchment of public workers and personnel officers in the 1994-2001 period seriously affected the performance of Phnom Penh Solid Waste Management Authority (PPSWA). Lacking personnel resources and contracted workers in the public sector, e.g. municipal and Khan authorities, privatization was the only available avenue to increase labor input in solid waste collection system [36]. CINTRI created the labor intensive employment; it has been the champion of solid waste collection since 2002. Workers are mostly migrant workers; some previously worked as waste pickers at the landfill. Another problem that the CINTRI waste collection company faces relates to uncertainty about 
the availability of crew and street sweepers. Many of these workers only work seasonally and they return to agricultural work during the farming season. Working conditions for those working in waste collection are unattractive and unhygienic; this is coupled with low wages.

The government has understood that the solid waste collection system run by the public sector was deficient due to low financial availability $[15,20,28]$. The low government salary, for instance ranging US\$75-150 in 1998-2002, was the biggest constraint to public sector performance as government job regulations were not effectively enforced. Therefore, the Phnom Penh municipality waste division had to provide a subsidy to those who were working at the landfill and incentivize inspection works. CINTRI was provided US $\$ 300$ for two inspectors of each Khan office for the monitoring and daily reporting assignment. This direct incentive from CINTRI was an attempt to address the monitoring process and the effectiveness of enforcement. Results from focus group discussions with LGAs indicated that the human capital of LGAs on waste management was limited as personnel resources were lacking and there was low capacity to handle newly assigned tasks. It can be concluded that waste collection drivers are included in human resources, security and employment.

\subsection{Public Perception}

Citizens (urban residents) are the largest and most critical category of stakeholders in waste management. They have a two-way relationship with waste services: the waste generator, sorting and managing curb-side storage, waste service clients, and information receivers and participants in community cleaning activities. The findings from recent studies show that the SWM situation has not been soundly addressed as the responses owing to $78.68 \%$ of service-connected households. The level of satisfaction is significantly associated with quality of services, frequency of collection and tipping fees; all coefficients are positive [37]. The service users are willing to pay more for improved collection services and reliability of service depending on the perception of PPP operational procedures [19]. The perception of PPP is based on the reliability of services, which is measured with six reliability variables [4]. The form of participation and cooperation for an improved living environment and waste services, in both connected and unconnected households, is positive, but some constraints and difficulties in accessing collection services and low collection frequency have not yet been solved. Most residents in suburban areas complain to CINTRI for not providing services adequately, except for those areas with high beneficiaries. Evidently, similar findings are indicated in $[20,35,37]$. It can be seen that the public perception of PPP is important for explaining the reliability of services.

\subsection{System Viability in SWM}

The viability of the entire institutional arrangement in Phnom Penh capital waste collection depends on financial sustainability. The collection of solid waste carried out by CINTRI under its 49-years term requires clear municipal and local government unit planning and regulation [15], because collection systems and disposal have large externalities and economies of scale that make competitive provision less viable [38]. The GS Engineering \& Construction Corp. projected that the service coverage will increase to cover $100 \%$ of city areas by 2020 and income will rise relatively. However, CINTRI has suggested increasing the fee, especially for those peri-urban district areas, as the cost of transport will also simultaneously rise. It was raised by CINTRI during the meeting with Phnom Penh Governor that the income losses of almost US\$20 million for service users was not paid to CINTRI during 2003-2016. Another problem facing PPCH is the construction of a new landfill as the current landfill will be full by 2020. The construction cost for a new landfill is estimated by the GS Engineering \& Construction Corp. as US\$120.1 million [19]. PPCH cannot afford this huge investment. Although there are financial shortfalls for the new construction of the landfill, PPCH is inclined not to allow CINTRI to increase the fees. Political interest would make the public sector decision weaker. There would be less commitment, and weaker enforcement and control for operators and users. 


\section{Priority Actions and Recommendations for Improving Public-Private Partnership on SWM}

Decentralization reform on SWM in Cambodia was entered in 2015. The reform was carried out to improve the situation of waste management and overall governance by transferring solid waste management functions to municipal and district administrations established by Sub-decree No. 113 on "Urban Solid Waste Management" [16]. With a new phase of decentralization, this case study found that reforms can be challenged to institutional, regulatory, technical and financial aspects or their combination. Private sector participation varies in its focus as it joins hand with the public sector to share the responsibilities. However, CINTRI cannot bridge the gap due to the limited quality of services. Based on the findings and critical review, the following recommendations can be made:

- Enhancing PPP and social acceptability. To reduce the deficiency of the waste collection system in Phnom Penh, the key measure for successful development of stakeholder participation is considering public interest, economic interest, preventing political manipulation and the will of municipal, Khan and Sangkat councils. The operational framework and procedure in PPP should be adjusted toward the system goals.

- Resource management of the public sector. LGA needs to be self-sustaining in its waste management program and strategy to reduce reliance on the private sector and also national government funding (subsidies).

- Continue monitoring and enforcing solid waste disposal regulations: implementing proper monitoring, controlling procedures and enforcing urban solid waste management regulations (e.g., sub-decree No. 113 on MSWM). These measures are necessary to reduce illegal dumping and should be enshrined in new urban waste management policies.

- Economic burden to LGAs and CINTRI. To reduce the fiscal and financial burden, operational processes for cost-recovery can be made through implementing an applicable fee that will adequately fund the LGAs and provide viable financing to CINTRI for a modern, sustainable system.

- Consideration of waste collection options. The requirements of management services, quality assessment, and priorities for cooperation between the contractor and the LGAs should be studied so that the options for the collection system are based on sound data.

- Building on strengths and working politically and flexible. Each Khan and municipal authorities should establish an effective mechanism to resolve constraints and obstacles by having regular technical working group meetings and discussions. The technical working groups established by joint ministries could provide the platform for involved parties to identify common ground and make discussion. In addition, the study suggests that LGAs should be working politically and flexibly based on their own approaches and strengths for re-allocation of resources and funds from national governments and multinational corporations.

- Capacity Building: Professionals and paraprofessionals in local government units are often not trained in many aspects of waste management, such as the future planning based on sound resource management performance. Proper training of LGAs' personnel dealing with waste management and service management is needed and critical in this transition, as also suggested by Seng et al. [37]; Spoann [15] and NLLC [17] in their case studies of Cambodia.

\section{Conclusions}

The main challenges of solid waste collection are service quality, institutional arrangement, stakeholder involvement, legitimacy issues, and labor and employment condition issues. The continued efforts to build the LGAs' capacity are of vital interest to governmental agencies in the transition period of SWM functional transfer to LGAs. Achieving urban waste management that will be effective in the long-term requires an integrated approach. The shortfalls of the institutional arrangement for PPP are clear indications of a service that lacks efficiency and effectiveness. This is the result of a lack of monitoring and evaluation of the PPP process. Due to the lack of a clear operational framework for this long-term contract, CINTRI is having difficulties widening service coverage 
and ensuring involvement from stakeholders, despite the MSWM decentralization to the LGAs. Consequently, inadequate waste collection frequency and tipping fee are the major public concerns and affect users' satisfaction with service. Meanwhile, the incidence of retrenchment of government officials and hiring low wages for crews led to unreliable service and unsound sustainable financing. A legal framework, no anti-competitive behavior, allowing the widening of ownership, and preventing public interests must be advised and adopted by municipal and local government. In this transition and specific local context, obligated responsibility, competitive tendering, and complete transparency with regards to financial accountability are essential for enhancing system viability. The study discovered that despite the government's decentralized policy commitment, waste management issues this city have not been fully addressed. However, this case may vary based on the political will and commitment of stakeholders including national and local government, the private sector and communities.

This study might, differences of cities notwithstanding, assist PPP in urban waste governance in a circular economy.

Author Contributions: Conceptualization, T.F. and C.L.; Data curation, V.S. and B.S.; Formal analysis, V.S.; Investigation, B.S. and M.Y.; Methodology, V.S.; Supervision, T.F.; Validation, B.S. and M.Y.; Writing-original draft, V.S.; and Writing—review and editing, T.F.

Funding: This research was funded by the Japan Society for the Promotion of Science (JSPS-RONPAKU) Program and University of Okayama, Japan.

Acknowledgments: The authors would like to thank anonymous reviewers and editors for their inspiring and constructive comments on this paper. The authors would also like to express gratitude and sincerely appreciate all Local Government Authorities, representative from private operators and Ministries for sharing information and participating in focus group discussions.

Conflicts of Interest: The authors declare no conflicts of interest.

\section{References}

1. Massoud, M.A.; El-Fadel, M.; Malak, A.A. Assessment of public vs private MSW management: A case study. J. Environ. Manag. 2003, 69, 15-24. [CrossRef]

2. Lasisi, K.S. An Appraisal of Municipal Solid Waste Management in Lagos State; Longman Publications: Ibadan, Nigeria, 2007.

3. Massoud, M.A.; El-Fadel, M. Public-private partnerships for solid waste management services. Environ. Manag. 2002, 30, 0621-0630. [CrossRef] [PubMed]

4. Aliu, I.R.; Adeyemi, O.E.; Adebayo, A. Municipal household solid waste collection strategies in an African megacity: Analysis of public private partnership performance in Lagos. Waste Manag. Res. 2014, 32, 67-78. [CrossRef] [PubMed]

5. Stoker, G. Conclusion: Privatization, urban government and the citizen. In The Privatization of Urban Services in Europe; Lorrain, D., Stoker, G., Eds.; Pinter: London, UK, 1997; pp. 204-212.

6. Spoann, V.; Nitivathananon, V.; Amin, A.T.M.N. An Assessment of Contracted Waste Service Collection Services: Case Study of Waste Collection in Siem Reap, Cambodia. In Proceedings of the International Conference on Integrated Solid Waste Management in Southeast Asia, Siem Reap, Cambodia, 5-7 July 2005; Coowanitwong, N., Shapkota, P., Pradhan, P., Nitivattananon, V., Eds.; Asian Institute of Technology: Bangkok, Thailand, 2006; pp. 245-260.

7. Ahmed, S.A.; Mansoor, A. Partnerships for solid waste management in developing countries: Linking theories to realities. Habitat Int. 2004, 28, 467-479. [CrossRef]

8. Post, J. The problems and potentials of privatising solid waste management in Kumasi, Ghana. Habitat Int. 1999, 23, 201-215. [CrossRef]

9. Denney, L. Working Politically in Practice Series—Case Study No. 8-Reforming Solid Waste Management in Phnom Penh; The Asia Foundation and the Overseas Development Institute: San Francisco, CA, USA, 2016.

10. Zurbrügg, C.; Caniato, M.; Vaccari, M. How assessment methods can support solid waste management in developing countries-A critical review. Sustainability 2014, 27, 545-570. [CrossRef]

11. Leitmann, J. Sustaining Cities: Environmental Planning and Management in Urban Design; McGraw-Hill: New York, NY, USA, 1999. 
12. Memon, M.A.; Imura, H.; Shirakwa, H. Reforms for managing urban environmental infrastructure and services in Asia. J. Environ. Dev. 2006, 15, 857-868. [CrossRef]

13. Bartone, C.R.; Leite, L.; Triche, T.; Schertenleib, R. Private Sector Participation in Municipal Solid Waste Service: Experience in Latin America. Waste Manag. Res. 1991, 9, 495-509. [CrossRef]

14. Spoann, V. Assessment of Contracted Waste Collection Services: Case Study in Siem Reap Municipality, Cambodia; VDM Verlag Dr Müller: Saarbrücken, Germany, 2010.

15. Spoann, V.; Takeshi, F.; Bandith, S.; Chanthy, L. Municipal solid waste management: Constraints and opportunities to improve capacity of local government authorities of Phnom Penh Capital. Waste Manag. Res. 2018, 36, 985-992. [CrossRef] [PubMed]

16. RGC (Royal Government of Cambodia). Sub-Decree on Solid Waste Management; Royal Government of Cambodia: Phnom Penh, Cambodia, 2015.

17. NLLC (National League of Local Councils). Survey Report on Waste Management Practices at Municipality/District Level; NLLC: Phnom Penh, Cambodia, 2016.

18. Vong, M. Progress and Challenges of Deconcentralization in Cambodia in Cambodia: The Case of Urban Solid Waste Management; CDRI: Phnom Penh, Cambodia, 2016.

19. COMPED. Study and Analysis on Institutional and Legal Framework of Solid Waste Management and the Development of the Current Landfill Operation and Management in Phnom Penh; Final Report for the Asian Foundation; COMPED: Phnom Penh, Cambodia, 2014.

20. Kum, V.; Sharp, A.; Harnpornchai, N. Improving the solid waste management in Phnom Penh city: A strategic approach. Waste Manag. 2005, 25, 101-109. [CrossRef] [PubMed]

21. RGC (Royal Government of Cambodia). National Strategic Development Plan 2014-2018; Royal Government of Cambodia: Phnom Penh, Cambodia, 2014.

22. JICA (Japanese International Cooperation Ageny). Drainage Improvement and Flood Protection in Phnom Penh-Achievements, Constraints and Plans; Final report; JICA: Phnom Penh, Cambodia, 2014.

23. Hul, S.; Kouk, F.; Soy, T.; Khoeurn, K. Solid Waste Generation and Life-Span with Credible Growth Forecasts Waste Generation, Volume and Composition; Final Report for the Asian Foundation; The Asian Foundation: Phnom Penh, Cambodia, 2015.

24. PPCH (Phnom Penh City Hall). Challenges and Opportunities for Phnom Penh Green City Development Plan, Presentation for the workshop on Cambodia Green City Development Plan, September 2015; PPCH: Phnom Penh, Cambodia, 2015.

25. GGGI (Global Green Growth Institute). Phnom Penh Green City Strategic Plan 2016-2025; ICEM consultants prepared for GGGI; GGGI: Phnom Penh, Cambodia, 2016.

26. Joseph, K. Stakeholder participation for sustainable waste management. Habitat Int. 2006, 30, 863-871. [CrossRef]

27. Visvanathan, C.; Trankler, J.; Zou, G.; Kurian, J.; Basnayake, B.F.; Chart, C. Municipal Solid Waste Management in Asia; Asian Regional Research Programme on Environmental Technology; Asian Institute of Technology: Bangkok, Thailand, 2004.

28. Van de Klundert, A.; Anschütz, J.; Scheinberg, A. Integrated Sustainable Waste Management: The Concept. Tools for Decision-Makers. Experiences from the Urban Waste Expertise Programme (1995-2001); WASTE: Gouda, The Netherlands, 2001.

29. Wilson, D.C.; Tormin, A.C. Planning Guide for Strategic Municipal Solid Waste Management in Major Cities in Low-income Countries; London, Environmental Resource Management for the World Bank/SDC: London, $\mathrm{UK}, 2000$.

30. Seng, B.; Hirayama, K.; Katayam-Hirayama, K.; Ochiai, S.; Kaneko, H. Scenario analysis of the benefit of municipal organic-waste composting over landfill, Cambodia. J. Environ. Manag. 2013, 114, $216-224$. [CrossRef] [PubMed]

31. PPDoE. Presentation on Phnom Penh Municipality of Phnom Penh for Phnom Penh Green City Strategic Plan; Department of Environment: Phnom Penh, Cambodia, 2016.

32. Seng, B.; Kaneko, H.; Hirayama, K.; Katayama-Hirayama, K. Municipal solid waste management in Phnom Penh, Capital city of Cambodia. Waste Manag. Res. 2010, 29, 491-500. [CrossRef] [PubMed]

33. Hoornweg, D.; Thomas, L. What a Waste: Solid Waste Management in Asia; Urban Development Sector Unit, East Asia and Pacific Region, World Bank: Washington, DC, USA, 1999. 
34. JICA. The Study on Solid Waste Management in the Municipality of Phnom Penh; Final Report; JICA: Phnom Penh, Cambodia, 2005.

35. MOE. Inventory Data on Waste Generation for Cambodia, Report for Department of Solid Waste Management; MOE: Phnom Penh, Cambodia, 2014.

36. Obirih-Opareh, N.; Post, J. Quality assessment of public and private modes of solid waste collection in Accra, Ghana. Habitat Int. 2002, 26, 95-112. [CrossRef]

37. Seng, B.; Fujiwara, T.; Spoann, V. Households' knowledge, attitudes, and practices toward solid waste management in suburbs of Phnom Penh, Cambodia. Waste Manag. Res. 2018, 36, 993-1000. [CrossRef] [PubMed]

38. Amin, A.T.M.N. Economic and Financial Considerations in Urban Environmental Management; UMP-Asia Occasional Paper 65; Urban Management Programme: Bangkok, Thailand, 2005.

(c) 2019 by the authors. Licensee MDPI, Basel, Switzerland. This article is an open access article distributed under the terms and conditions of the Creative Commons Attribution (CC BY) license (http://creativecommons.org/licenses/by/4.0/). 